\title{
Acrylamide-Induced Changes in Femoral Bone Microstructure of Mice
}

\author{
A. SAROCKA ${ }^{1}$, R. BABOSOVA ${ }^{1}$, V. KOVACOVA ${ }^{1}$, R. OMELKA ${ }^{2}$, M. SEMLA ${ }^{3}$, \\ E. KAPUSTA ${ }^{3}$, Z. GOC ${ }^{3}$, G. FORMICKI ${ }^{3}$, M. MARTINIAKOVA ${ }^{1}$
}

${ }^{1}$ Department of Zoology and Anthropology, Faculty of Natural Sciences, Constantine the Philosopher University in Nitra, Slovak Republic, ${ }^{2}$ Department of Botany and Genetics, Faculty of Natural Sciences, Constantine the Philosopher University in Nitra, Slovak Republic, ${ }^{3}$ Department of Animal Physiology and Toxicology, Institute of Biology, Faculty of Geography and Biology, Pedagogical University in Cracow, Poland

Received October 19, 2016

Accepted May 2, 2017

On-line September 22, 2017

\section{Summary}

Acrylamide $(A A)$ is one of the most common toxins in foods. Its effect on bone microstructure has not been investigated. The aim of our study was to analyze the impact of acute exposure to AA on femoral bone microstructure in mice. Adult animals were treated perorally with 2 doses of AA (E1 group, $1 \mathrm{mg} / \mathrm{kg}$ b.w.) in a 24-h period and with 3 doses of AA (E2 group, $1 \mathrm{mg} / \mathrm{kg}$ b.w.) in a 48-h period. Mice exposed to AA had smaller sizes of primary osteon's vascular canals. Secondary osteons were significantly smaller in mice from E2 group; however their increased number (from $38 \%$ to $77 \%$ ) was identified in both E1 and E2 groups. In these groups, a higher number of resorption lacunae (from $100 \%$ to $122 \%$ ) was also found. The values for bone volume, trabecular number were increased and that for trabecular separation was decreased in mice administered AA. Significantly higher value of bone surface was observed in mice from E1 group whereas trabecular thickness was increased in E2 group. The effect of $A A$ on microstructure of compact and trabecular bone tissues is different. In our study, one dose of AA was used and acute effects of AA were investigated. Therefore, further studies are needed to study mechanisms by which AA acts on bone.

\section{Key words}

Acrylamide • Bone • Mouse • Microstructure

\section{Corresponding author}

A. Sarocka, Department of Zoology and Anthropology, Faculty of Natural Sciences, Constantine the Philosopher University in Nitra,
Nábrežie mládeže 91, 94974 Nitra, Slovak Republic. E-mail: sarocka.anna@gmail.com

Acrylamide (AA, CAS Reg. No. 79-06-1), $\alpha, \beta$-unsaturated reactive molecule, is an odorless crystalline solid (Erikson 2005, Parzefall 2008, Wei et al. 2014). Besides its utilization in industry, AA is a contaminant in foods prepared during high-temperature cooking (Pedreschi et al. 2014) like fried potatoes, bakery products, breakfast cereals and coffee. It can also be absorbed across the skin (Li et al. 2015).

There are many reports demonstrating various toxic effects of AA in experimental animals (Takami et al. 2012), including reproductive toxicity (Park et al. 2010), genotoxicity ( $\mathrm{Li}$ et al. 2015) and neurotoxicity (Tyl et al. 2000). AA is a substance classified as a probable human carcinogen (Mucii and Wilson 2008).

Although AA belongs to the most commonly consumed toxins by humans, its effect on bone microstructure is still unknown. Therefore, our study was aimed to determine femoral bone microstructure of adult mice after an acute peroral exposure to AA.

In our experiment, twelve clinically healthy 12-week-old Swiss mice (males) were used. The animals were obtained from the accredited experimental laboratory of the Pedagogical University in Cracow. Adult mice were randomly divided into three experimental groups of 4 animals each. In E1 group 
males were treated perorally with 2 doses of AA $(1 \mathrm{mg} / \mathrm{kg}$ b.w.) in a $24-\mathrm{h}$ period. In E2 group mice received 3 doses of AA ( $1 \mathrm{mg} / \mathrm{kg}$ b.w.) during a 48-h period. The dose of AA was chosen on the basis of the experiment conducted by Doerge et al. (2005) and our previous experiences (Kopańska et al. 2015). AA was dissolved in physiological saline. The third group without AA administration served as a control one (group C). All the applied procedures were approved by the First Local Ethic Committee on Experiments on Animals in Cracow (resolution number 175/2012).

Three hours after the last dose of AA, all mice were killed and their femora were used for microscopical analyses. Thin sections from femora $(70-80 \mu \mathrm{m})$ were prepared according to the methodology of Martiniaková et al. (2008). The qualitative histological characteristics of the compact bone were determined according to the internationally accepted classification systems of Enlow and Brown (1956) and Ricqlés et al. (1991). The quantitative (morphometrical) parameters of the compact bone were assessed using the software Motic Images Plus 2.0 ML (Motic China Group Co., Ltd., Xiamen, China). We measured area, perimeter, maximum and minimum diameters of the vascular canals of primary osteons, Haversian canals and secondary osteons in all views (anterior, posterior, medialis, lateralis) of thin sections.

Morphometrical characteristics of the trabecular bone and cortical bone thickness were determined using microCT system ( $\mu$ CT 50, Scanco Medical, Brüttisellen, Switzerland). $\mu \mathrm{CT}$ studies were performed on the distal femora to image trabecular bone morphometry. Trabecular bone was analyzed in a region of interest starting $1.2 \mathrm{~mm}$ from the end of the growth plate and extending $1.5 \mathrm{~mm}$. Following parameters were measured: bone volume, trabecular number, trabecular thickness, trabecular separation and bone surface. Cortical bone thickness was analyzed in a region of interest starting $5.2 \mathrm{~mm}$ from the end of the growth plate and extending $1.5 \mathrm{~mm}$ at femoral midshaft.

Statistical analysis was performed using SPSS 8.0 software. All data were expressed as mean \pm standard deviation. The unpaired Games-Howell's and/or Tukey's tests were used for establishing statistical significance $(\mathrm{P}<0.05)$ among all groups.

Endosteal surfaces of femora in mice from the $\mathrm{C}$ group consisted of non-vascular bone tissue (in anterior, medialis and lateralis views), which contained cellular lamellae and osteocytes. In pars posterior, primary vascular radial bone tissue was observed. This tissue included vascular canals (branching or non-branching) radiating from the marrow cavity. In the middle parts of the compact bone (mainly in anterior and lateralis views), a few primary osteons and several secondary osteons were identified. Non-vascular bone tissue was found only in pars medialis. Finally, the periosteal border was composed of non-vascular bone tissue (Table 1). These results are in accordance to those of other researchers (Treuting and Dintzis 2011, Enlow and Brown 1956, Reim et al. 2008).

In our study, differences in compact bone microstructure of mice from the E1 and E2 groups were identified. Mice from these groups had more intact secondary osteons (from $38 \%$ to $77 \%$ ) in the middle part of the compact bone. In addition, more resorption lacunae (from $100 \%$ to $122 \%$ ) were found in pars anterior of their periosteal border (Table 1).

The changes mentioned above can be explained as an adaptive response of the compact bone to AA toxicity. The results by Raju et al. (2015) showed that AA increases the oxidative stress and peroxidation of the lipids. Oxidative stress is characterized by an increased level of reactive oxygen species, which enhance bone resorption (Bai et al. 2005) and osteoclastogenesis (Garret et al. 1990). Also, a biochemical link between increased lipid peroxidation and reduced bone mineral density has been described (Basu et al. 2001).

In total, 353 vascular canals of primary osteons, 54 Haversian canals and 54 secondary osteons were measured. The results are summarized in Table 1. All measured variables (area, perimeter, maximal and minimal diameters) of the primary osteon's vascular canals were significantly decreased $(\mathrm{P}<0.05)$ in groups $\mathrm{E} 1$ and $\mathrm{E} 2$ when compared to the $\mathrm{C}$ group. Significant differences were also found between E1 and E2 groups. Haversian canals values did not differ significantly among all groups. On the contrary, the values of the secondary osteons were significantly smaller $(\mathrm{P}<0.05)$ in mice from the E2 group. Significant differences were also demonstrated between the E1 and E2 groups.

Vasoconstriction of the vascular canals of primary osteons in mice exposed to AA could be associated with deleterious effect of AA on blood vessels. According Raju et al. (2015) AA decreases the high density lipoprotein (HDL). Low HDL is associated with narrowing or blockage of the arteries and vessels (Miller et al. 1992). 
Table 1. Results of compact bone microstructure in mice from the E1, E2 and C groups.

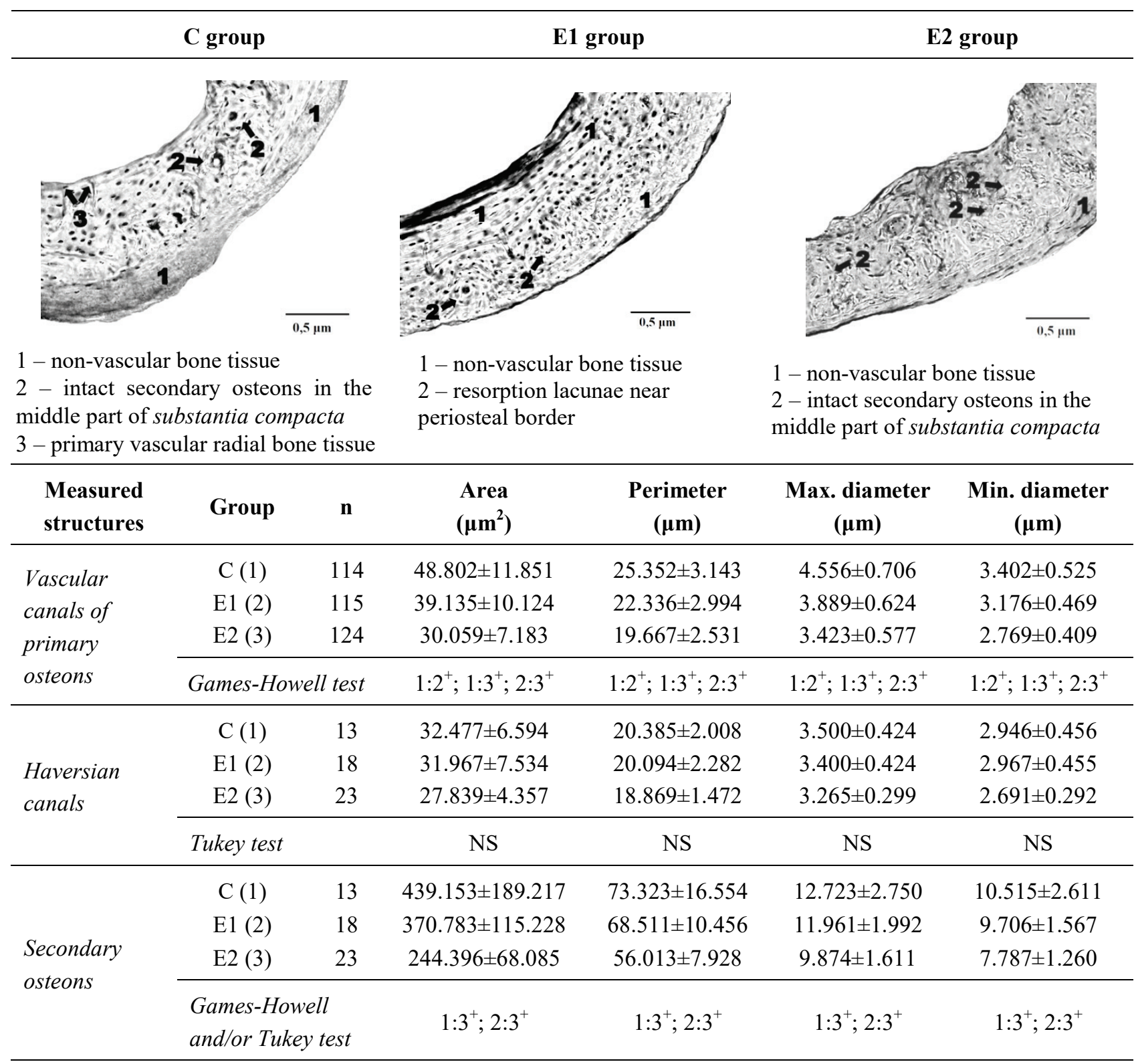

$\mathrm{n}$, number of measurements; ${ }^{+} \mathrm{P}<0.05 ; \mathrm{NS}$, non-significant differences.

Significantly reduced sizes of the secondary osteons in mice from the E2 group could be related to decreased bone mineralization. The results by Wauquier et al. (2009) showed that AA increased the level of the hydrogen peroxide. The hydrogen peroxide significantly decreases the bone mineralization (Arai et al. 2007).

Our results also showed an insignificant effect of AA administration on cortical bone thickness $(0.18 \pm 0.009 \mathrm{~mm}, \quad 0.19 \pm 0.006 \mathrm{~mm}, \quad 0.17 \pm 0.022 \mathrm{~mm})$ in mice from the E1, E2 and C groups, respectively.

In the trabecular bone, the values for bone volume and trabecular number were significantly increased $(\mathrm{P}<0.05)$ in mice administered AA. On the contrary, the value for trabecular separation was significantly decreased in these mice. Significantly higher value $(\mathrm{P}<0.05)$ of bone surface was observed in mice from the E1 group whereas trabecular thickness was increased in mice from the E2 group. The results are summarized in Table 2. Representative reconstructed 3D images of the trabecular bone are also illustrated in Table 2.

According to Alturfan et al. (2011) AA significantly increases synthesis of tissue collagen in various parenchymatous organs (brain, lung, liver, kidney, testes). The collagen is a major organic component of mineralized bone matrix. Also, the results 
Table 2. Results of trabecular bone microstructure in mice from the E1, E2 and C groups.

\begin{tabular}{|c|c|c|c|c|}
\hline & C group (1) & E1 group (2) & E2 group (3) & Tukey test \\
\hline & $1 \mathrm{~mm}$ & $1 \mathrm{~mm}$ & 11 & \\
\hline BV/TV (\%) & $0.08 \pm 0.02$ & $0.13 \pm 0.01$ & $0.18 \pm 0.04$ & $1: 2^{+} ; 1: 3^{+}$ \\
\hline Tb. N. (1/mm) & $3.97 \pm 0.45$ & $4.76 \pm 0.09$ & $4.89 \pm 0.48$ & $1: 2^{+} ; 1: 3^{+}$ \\
\hline Tb. Th. (mm) & $0.04 \pm 0.0014$ & $0.04 \pm 0.0013$ & $0.05 \pm 0.0019$ & $1: 3^{+} ; 2: 3^{+}$ \\
\hline Tb.Sp. (mm) & $0.25 \pm 0.03$ & $0.20 \pm 0.01$ & $0.19 \pm 0.02$ & $1: 2^{+} ; 1: 3^{+}$ \\
\hline$B s .\left(m^{2}\right)$ & $14.75 \pm 5.29$ & $22.63 \pm 1.68$ & $21.93 \pm 4.69$ & $1: 2^{+}$ \\
\hline
\end{tabular}

n, number of measurements; ${ }^{+} \mathrm{P}<0.05$; NS, non-significant differences; BV/TV, bone volume; Tb. N., trabecular number; Tb. Th., trabecular thickness; Tb. Sp., trabecular separation; Bs., bone surface.

by Raju et al. (2015) showed that AA increases a concentration of calcium, an important component of hydroxyapatite crystals (Koutsopoulos 2002), in the blood. Therefore, we suppose that AA could influence the trabecular bone microstructure through these mechanisms.

Our results suggest that acute peroral administration to AA significantly affects microstructure of compact and trabecular bone tissues. However, the impact of AA on microarchitecture of these tissues is different. The compact bone is more resorbed, trabecular bone is more robust. Therefore, it would be necessary to study mechanisms by which AA acts on bone. These mechanisms remain unclear. Anyway, the most evident changes were observed in mice treated with 3 doses of $\mathrm{AA}$ in a 48 -h period. It can be concluded that the effect of AA on bone microstructure depends on the degradation rate. Our findings provide the first information related to AA impact on bone microarchitecture in experimental animals.

There are several limitations to our study. First, only one dose of AA was used. Second, we investigated only acute effect of AA on bone microstructure. Therefore, further studies are needed to find out the complex effect of AA in the bone.

\section{Conflict of Interest}

There is no conflict of interest.

\section{Acknowledgements}

This work was supported by the Slovak Research and Development Agency under the contract No. SK-PL2015-0032. The study was also supported by the projects VEGA 1/0653/16 and KEGA 031UKF-4/2016.

\section{References}

ALTURFAN AA, TOZAN-BECEREN A, SEHIRLI AÖ, DEMIRALP E, SENER G, OMURTAG GZ: Resveratrol ameliorates oxidative DNA damage and protects against acrylamide-induced oxidative stress in rats. Mol Biol Rep 39: 4589-4596, 2012.

ARAI M, SHIBATA Y, PUGDEE K, ABIKO Y, OGATA Y: Effects of reactive oxygen species (ROS) on antioxidant system and osteoblastic differentiation in MC3T3- E1 cells. UIBMB Life 59: 27-33, 2007.

BAI X, LU D, LIU A, ZHANG Z, LI X, ZOU Z, ZENG W, CHENG B, LUO S: Reactive oxygen species stimulates receptor activator of NF-kB ligand expression in osteoblast. J Biol Chem 280: 17497-17506, 2005.

BASU S, MICHAELSSON K, OLOFSSON H, JOHANSSON S, MELHUS H: Association between oxidative stress and bone mineral density. Biochem Biophys Res Commun 288: 275-279, 2001.

DOERGE DR, DA COSTA GG, MCDANIEL LP, CHURCHWELL MI, TWADDLE NC, BELAND FA: DNA adducts derived from administration of acrylamide and glycidamide to mice and rats. Mutat Res 580: 131-141, 2005. 
ENLOW DH, BROWN SO: Comparative histological study of fossil and recent bone tissues. Part I. Tex J Sci 8: 405, 1956.

ERIKSON J: Acrylamide in Food Products: Identification, Formation and Analytical Technology. Ph. D. Thesis. Stockholm: Stockholm University, Department of Environmental Chemistry. 91, 2005.

GARRET IR, BOYCE BF, OREFFO RO, BONEWALD L, POSER J, MUNDY GR: Oxygen-derived free radicals stimulate osteoclastic bone resorption in rodent bone in vitro and in vivo. J Clin Invest 85: 632-639, 1990.

KOPAŃSKA M, LUKÁČ N, KAPUSTA E, FORMICKI G: Acrylamide influence on activity of acetylcholinesterase, thiol groups, and malondialdehyde content in the brain of Swiss mice. J Biochem Mol Toxicol 29: 472-478, 2015.

KOUTSOPOULOS S: Synthesis and characterization of hydroxyapatite crystals: a review study on the analytical methods. J Biomed Mater Res 62: 600-612, 2002.

LI J, LI D, YANG Y, XU T, LI P, HE D: Acrylamide induces locomotor defects and degeneration of dopamine neurons in Caenorhabditis elegans. $J$ Appl Toxicol 36: 60-67, 2015.

MARTINIAKOVÁ M, OMELKA R, GROSSKOPF B, SIROTKIN AV, CHRENEK P: Sex-related variation in compact bone microstructure of the femoral diaphysis in juvenile rabbits. Acta Vet Scand 50: 15, 2008.

MILLER M, SEIDLER A, KWITEROVICH PO, PEARSON TA: Long-term predictors of subsequent cardiovascular events with coronary artery disease and "desirable" levels of plasma total cholesterol. Circulation 86: 1165$1170,1992$.

MUCCI LA, WILSON KM: Acrylamide intake through diet and human cancer risk. J Agric Food Chem 56: 6013-6019, 2008.

PARK HR, KIM MS, KIM SJ, PARK M, KONG KH, KIM HS, KWACK SJ, KANG TS, KIM SH, KIM HS, LEE J: Acrylamide induces cell death in neural progenitor cells and impairs hippocampal neurogenesis. Toxicol Lett 193: 86-93, 2010.

PARZEFALL W: Minireview on the toxicity of dietary acrylamide. Food Chem Toxicol 46: 1360-1364, 2008.

PEDRESCHI F, MARIOTTI MS, GRANBY K: Current issues in dietary acrylamide: formation, mitigation and risk assessment. J Sci Agric 94: 9-20, 2014.

RAJU J, ROBERTS J, TAYLOR M, PATRY D, CHOMYSHYN E, CALDWELL D, COOKE G, MEHTA R: Toxicological effects of short-term dietary acrylamide exposure in male F344 rats. Environ Toxicol Pharmacol 39: 85-92, 2015.

REIM NS, BREIG B, STAHR K, EBERLE J, HOEFLICH A, WOLF E, ERBEN RG: Cortical bone loss in androgendeficient aged male rats is mainly caused by increased endocortical bone remodeling. $J$ Bone Miner Res 23: 694-704, 2008.

RICQLÉS AJ, MEUNIER FJ, CASTANET J, FRANCILLON-VIEILLOT H: Comparative microstructure of bone. In: Bone 3, Bone Matrix and Bone Specific Products. HALL BK (ed.), Boca Raton: CRC Press, 1991, pp 1-78.

TAKAMI S, IMAI T, CHO YM, OGAWA K, HIROSE M, NISHIKAWA A: Juvenile rats do not exhibit elevated sensitivity to acrylamide toxicity after oral administration for 12 weeks. $J$ Appl Toxicol 32: 959-967, 2012.

TREUTING PM, DINTZIS SM: Comparative Anatomy and Histology: a Mouse and Human Atlas. Academic Press, 2011, pp 1-480.

TYL RW, FRIEDMAN MA, LOSCO PE, FISCHER LC, JOHNSON KA, STROTHER DE, WOLF CH: Rat two-generation reproduction and dominant lethal study of acrylamide in drinking water. Reprod Toxicol 14: 385-401, 2000.

WAUQUIER F, LEOTOING L, COXAM V, GUICHEUX J, WITTRANT Y: Oxidative stress in bone remodeling and disease. Trends Mol Med 15: 468-477, 2009.

WEI Q, LI J, LI X, ZHANG L, SHI F: Reproductive toxicity in acrylamide-treated female mice. Reprod Toxicol 46: 121-128, 2014. 